\title{
Layered double hydroxides modify the reaction of sodium silicate-activated slag cements
}

Xinyuan Ke BEng, PhD

Postdoctoral Research Associate, Department of Materials Science and Engineering, The University of Sheffield, Sheffield, UK

(Orcid:0000-0002-1239-6861)

Susan A. Bernal BEng, DEng

Research Fellow, Department of Materials Science and Engineering,

The University of Sheffield, Sheffield, UK (Orcid:0000-0002-9647-3106)
John L. Provis BE (Hons), BSc, PhD

Professor, Department of Materials Science and Engineering, The University of Sheffield, Sheffield, UK (corresponding author: j.provis@sheffield.ac.uk) (Orcid:0000-0003-3372-8922)

The impact of adding two types of layered double hydroxides (LDHs), commercial hydrotalcite (HT) and its thermally treated form (CLDH), on the reaction kinetics and phase assemblage development of a sodium silicate-activated slag cement was investigated. The reaction kinetics of LDH-modified cements was assessed by isothermal calorimetry, and the results were correlated with in situ attenuated total reflection Fourier transform infrared spectroscopy results collected over the first days of reaction, to identify the structural evolution of the main binding phase forming in these cements: a sodium-containing calcium aluminosilicate hydrate (C-(N)-A-S-H)-type gel. The addition of either HT or CLDH into sodium silicate-activated slag paste accelerates the precipitation of reaction products and increases the formation of HT in these cements, without causing significant changes to the C-(N)-A-S-H binding phase. This is extremely relevant in terms of the durability of alkali-activated slag cements, as a higher content of the HT-like phase has the potential to reduce their chloride permeability and enhance carbonation resistance.

\section{Introduction}

Layered double hydroxides (LDHs), with the general formula of $\left[\mathrm{M}^{\mathrm{II}}{ }_{1-x} \mathrm{M}^{\mathrm{III}}{ }_{x}(\mathrm{OH})_{2}\right]^{x+}\left[\mathrm{A}^{m-}\right]_{x / m} \cdot n \mathrm{H}_{2} \mathrm{O}$ (where $\mathrm{M}^{\mathrm{II}}$ represents divalent metal cations, $\mathrm{M}^{\mathrm{III}}$ represents trivalent metal cations, $\mathrm{A}^{m-}$ represents anions and $0<x<1$ ), are a group of minerals that have a positively charged layered structure due to the partial substitution of divalent by trivalent cations in a brucite-like lattice structure, which brings a capacity for anion exchange in the interlayer. ${ }^{1-3}$ Calcined layered double hydroxides (CLDHs), produced from thermally treated LDHs, can recrystallise to produce LDHs in an aqueous environment while accommodating available anions from the solution into their interlayers, including chloride $\left(\mathrm{Cl}^{-}\right)$and carbonate $\left(\mathrm{CO}_{3}{ }^{2-}\right){ }^{4-7}$ This makes CLDH a promising chemical additive for improving the durability of cement and concrete against both carbonation and chloride ingress. ${ }^{7-9}$ The inclusion of CLDH in sulfoaluminate cement and in Portland cement has shown the potential to slow down the ingress of carbon dioxide $\left(\mathrm{CO}_{2}\right)$ and chloride from the environment into hardened monolithic samples, ${ }^{10,11}$ yielding a higher chloride and carbon dioxide binding capacity. ${ }^{9}$

Alkali-activated cements are gaining interest as a sustainable and technically sound alternative to traditional Portland cement for the production of concretes. ${ }^{12,13}$ Alkali-activated slag cements are formed by the reaction between blast-furnace slag and an alkaline activator. Hydrotalcite (HT)-like (Mg,Al)-LDHs are commonly identified as a reaction product which forms in these cements when the magnesium oxide $(\mathrm{MgO})$ content in the raw material is higher than $5 \mathrm{wt} . \%$, being generated along with the sodium-rich calcium aluminosilicate hydrate (C-(N)-A-S-H)-type gels that dominate the structure of these cements. ${ }^{14-16}$
Recent studies incorporating CLDH into alkali-activated slag cements, using sodium carbonate as the activator, demonstrated that this addition could efficiently accelerate the kinetics of the reaction of these systems by increasing the $\mathrm{pH}$ of the pore solution, capturing carbonate anions and aiding the increased formation of HT. ${ }^{17}$ This smart chemical additive also promotes compressive strength development, refines the microstructure of the binder ${ }^{18}$ and significantly increases the durability of these cements in terms of carbonation and chloride ingress. ${ }^{18,19}$ The unique benefits of CLDH addition in controlling the reaction kinetics and phase assemblage of alkali-activated slag cements are due to the compatibility between CLDH and these cements, which might also be the case when using other alkali sources as activators, such as sodium silicate.

Sodium silicate-activated slag (AAS) cement is the most widely produced and studied alkali-activated system. The formation of HT-like phase in AAS cement is largely controlled by the magnesium oxide content of the slag used. ${ }^{8,20}$ An HT-like phase with hydroxide $\left(\mathrm{OH}^{-}\right)$as interlayer anions and a magnesium $(\mathrm{Mg})$ /aluminium (Al) ratio of around 2 is normally formed in AAS cement binders, ${ }^{20,21}$ because of the absence of carbonate ions in the sodium silicate activator. Therefore, the uptake of dissolved carbonate ions by CLDH, which is the process by which this additive accelerates the kinetics of reaction in sodium carbonate-activated slag, ${ }^{17}$ cannot take place in an AAS system. This might also suggest that for AAS cement, the addition of HT could have a similar effect as that of the thermally treated HT $(\mathrm{CLDH})$. Since CLDH is normally produced from HT through thermal processes, ${ }^{22,23}$ the use of HT instead of CLDH would be a more energy-efficient option for AAS cement. 
Layered double hydroxides modify the reaction of sodium silicate-activated slag cements Ke, Bernal and Provis
In this study, $5 \mathrm{wt} \%$ of either thermally treated HT (CLDH) or commercial HT was added into sodium silicate-activated slag pastes. The influence of both CLDH and HT on the kinetics of the reaction and early-age structure evolution of these cements was investigated. The phase assemblage of cements aged for up to $180 \mathrm{~d}$ was also investigated using X-ray diffraction (XRD) and scanning electron microscopy, coupled with energy-dispersive $\mathrm{X}$ ray analysis (EDX).

\section{Materials and methods}

\subsection{Materials and sample preparation}

The composition of the ground granulated blast-furnace slag used in this study is shown in Table 1. The Blaine fineness of this slag was $5056 \pm 22 \mathrm{~cm}^{2} / \mathrm{g}$, and its average particle size determined by laser diffraction, $d_{50}$, was $11 \cdot 2 \mu \mathrm{m}$. The sodium silicate activator used in this study was prepared by pre-dissolving commercial analytical grade sodium metasilicate $\left(\mathrm{Na}_{2} \mathrm{SiO}_{3}\right)$ powder (SigmaAldrich, sodium metasilicate $\geq 99 \cdot 5 \%)$ into distilled water $\left(\mathrm{H}_{2} \mathrm{O}\right)$ (cooled down to room temperature prior to use). Commercial HT (Sigma-Aldrich) was used as the LDH addition into the mixes, and calcined HT (CLDH) was prepared by thermally treating this $\mathrm{HT}$ at $500^{\circ} \mathrm{C}$, following the preparation method described in the authors' previous work. ${ }^{17}$

AAS pastes with the addition of either CLDH or HT were produced according to the formulations shown in Table 2. This mix design was chosen based on previous studies where the activator dose and water-to-binder ratio were optimised. ${ }^{7,24}$ The slag paste prepared without any chemical addition is referred to as 'reference' throughout the paper. Samples prepared with $5 \mathrm{wt} . \%$ addition of CLDH or HT (by mass of anhydrous slag) are referred to as modified samples. Samples were cured in sealed centrifuge tubes at $20^{\circ} \mathrm{C}$ until testing (up to $180 \mathrm{~d}$ ), unless otherwise noted.

\subsection{Testing methods}

The kinetics of the reaction of alkali-activated slag pastes was evaluated by isothermal calorimetry using a TAM Air isothermal calorimeter at a base temperature of $25 \pm 0 \cdot 02^{\circ} \mathrm{C}$. The fresh cement mix was prepared by external hand-mixing for $3 \mathrm{~min}$, weighed into an ampoule and immediately placed in the calorimeter to record heat flow. Samples of approximately $20 \mathrm{~g}$ of paste were used, and heat flow was recorded during the first $300 \mathrm{~h}$ of reaction.

The early-age evolution of the alkali-activated slag pastes was studied using a PerkinElmer Frontier Mid Fourier transform infrared spectroscopy (FTIR) spectrometer with an attenuated total reflection (ATR) attachment, where freshly prepared pastes were mounted onto the diamond ATR crystal, and spectra were recorded at regular time intervals for $48 \mathrm{~h}$. Spectra were taken in the absorbance mode from 2000 to $600 \mathrm{~cm}^{-1}$ at a resolution of $1 \mathrm{~cm}^{-1}$. During the test, the paste samples were covered with cling film to prevent drying and/or carbonation.

The phase assemblage of these cements was determined up to $180 \mathrm{~d}$ of curing. XRD patterns were collected using a Bruker D2 Phaser instrument with copper $(\mathrm{Cu}) \mathrm{K} \alpha$ radiation and a nickel filter. A step size of $0.02^{\circ}$ and a counting time of $3 \mathrm{~s} / \mathrm{step}$, from 5 to $55^{\circ} 2 \theta$, were used. The microstructure of the hardened pastes was analysed by environmental scanning electron microscopy (ESEM) and EDX, using a Hitachi benchtop ESEM TM3030 with a Bruker Quantax 70 X-ray microanalysis detector. An acceleration voltage of $15 \mathrm{kV}$ and a working distance of $8 \mathrm{~mm}$ were applied. Polished but uncoated samples were used for both backscattered electron (BSE) imaging and EDX analysis. Over 50 points (EDX spots) were recorded per sample at each age and formulation.

\section{Results}

\subsection{Kinetics of reaction}

Figure 1 shows the heat flow and total heat release of AAS paste, in comparison with those of pastes with $5 \mathrm{wt} . \% \mathrm{CLDH}$ and $5 \mathrm{wt} \%$ HT, during the first $60 \mathrm{~h}$ of reaction. The heat evolution from the samples prepared shows four distinct stages: a pre-induction period, induction period, acceleration period and deceleration period. These stages correspond respectively to the surface wetting of the slag particle, the metastable dormant period, the onset of precipitation of

Table 1. Chemical composition of anhydrous ground granulated blast-furnace slag, determined by X-ray fluorescence

\begin{tabular}{|c|c|c|c|c|c|c|c|c|c|c|c|}
\hline & $\begin{array}{l}\text { Calcium } \\
\text { oxide } \\
(\mathrm{CaO})\end{array}$ & $\begin{array}{l}\text { Silicon } \\
\text { dioxide } \\
\left(\mathrm{SiO}_{2}\right)\end{array}$ & $\begin{array}{c}\text { Aluminium } \\
\text { oxide } \\
\left(\mathrm{Al}_{2} \mathrm{O}_{3}\right)\end{array}$ & $\begin{array}{c}\text { Magnesium } \\
\text { oxide } \\
\text { (MgO) }\end{array}$ & $\begin{array}{l}\text { Sulfur } \\
\text { trioxide } \\
\left(\mathrm{SO}_{3}\right)\end{array}$ & $\begin{array}{c}\text { Iron (III) } \\
\text { oxide } \\
\left(\mathrm{Fe}_{2} \mathrm{O}_{3}\right)\end{array}$ & $\begin{array}{c}\text { Titanium } \\
\text { dioxide } \\
\left(\mathrm{TiO}_{2}\right)\end{array}$ & $\begin{array}{l}\text { Manganese } \\
\text { (II) oxide } \\
\text { (MnO) }\end{array}$ & $\begin{array}{l}\text { Potassium } \\
\text { oxide } \\
\left(\mathrm{K}_{2} \mathrm{O}\right)\end{array}$ & Others & LOI \\
\hline Content: \% & $41 \cdot 3$ & $36 \cdot 0$ & $11 \cdot 3$ & 6.5 & 0.7 & 0.3 & 0.5 & 0.3 & 0.4 & 0.3 & $2 \cdot 0$ \\
\hline
\end{tabular}

LOI, loss on ignition at $1000^{\circ} \mathrm{C}$. All elements are represented on an oxide basis regardless of their oxidation state in the slag

Table 2. Mix designs of the pastes assessed

\begin{tabular}{lcccccc} 
Sample ID & Slag: $\mathbf{g}$ & Sodium metasilicate: $\mathbf{g}$ & Water: $\mathbf{g}$ & CLDH: $\mathbf{g}$ & HT: g & w/b \\
\hline Reference & 100 & 7 & $42 \cdot 8$ & - & - & 0.40 \\
$5 \%$ CLDH & 100 & 7 & $42 \cdot 8$ & 5 & - & 0.40 \\
$5 \%$ HT & 100 & 7 & $42 \cdot 8$ & - & 5 & 0.40
\end{tabular}

${ }^{a}$ w/b, water/binder mass ratio (where binder is defined as slag + mass of sodium silicate) 


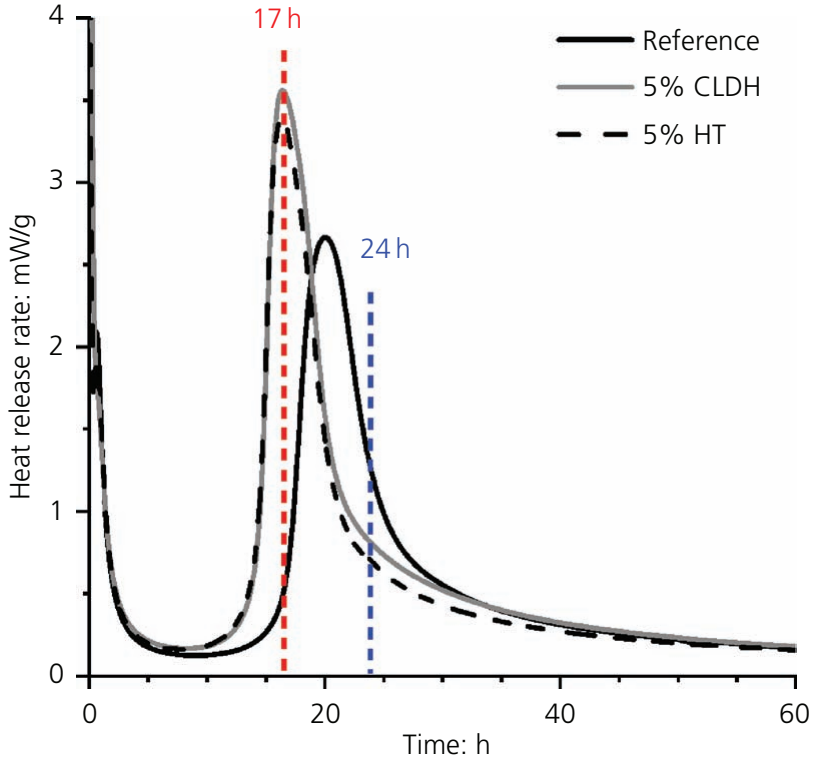

(a)

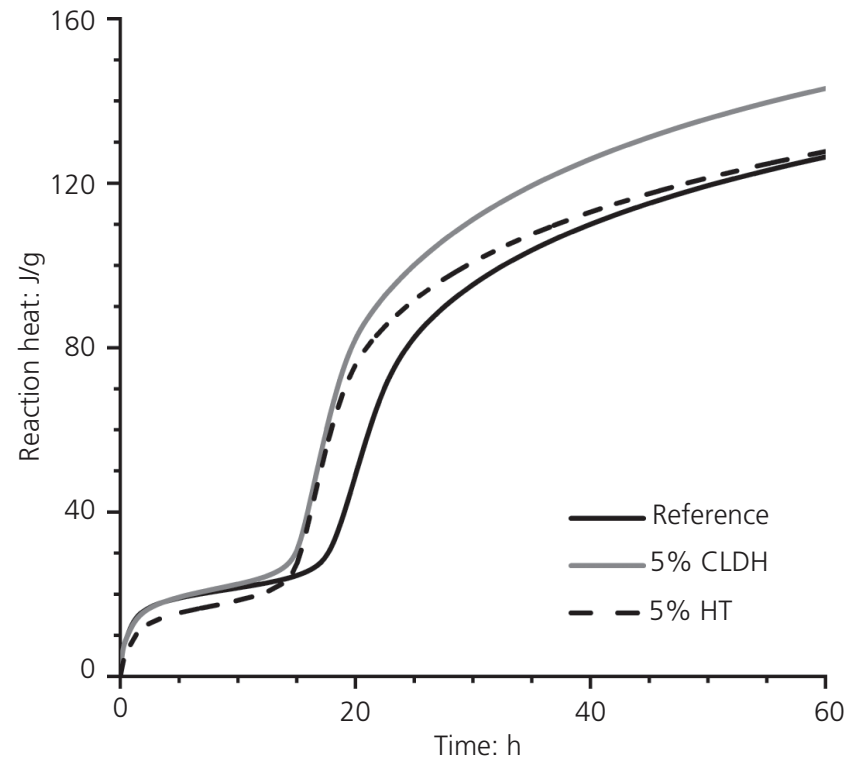

(b)

Figure 1. Isothermal calorimetry data on (a) heat release flow and (b) total heat release, for AAS paste, as a function of the LDH addition. The data are normalised by the total mass of the slag in the paste

the main reaction products and the gradual slowing down of the reaction rate after setting. ${ }^{8,25,26}$ The heat release from the AAS paste assessed here showed reaction stages consistent with what have been reported previously in the literature where a slag with a similar chemical composition was used. ${ }^{8,26-28}$ However, a faster reaction was reported where a much higher activator dose and/or lower water-to-binder ratio was used, ${ }^{26,28}$ while a slower reaction was observed where a lower activator dose was used. ${ }^{27}$ Because the chemistry of the alkali-activation process is very different from that of Portland cement hydration, it is difficult to draw detailed mechanistic parallels between these two processes. The total heat release corresponds to the cumulative reaction heat generated during these four stages.

In Figure 1(a), it can be seen that the modified AAS pastes (with CLDH or HT addition) present shorter induction periods and more intense acceleration periods, compared with the reference AAS pastes. Slight differences in the kinetics of reaction were identified in pastes produced with CLDH and with HT, with higher maximum heat flow rates observed when using 5\% CLDH. This is consistent with a higher degree of reaction, indicated by the higher total heat release (Figure 1(b)), in CLDH-modified AAS pastes compared with the other pastes tested. This higher total heat release is attributed to the slightly increased rate of heat release during both the pre-induction period and the deceleration period, compared with the other specimens. The former is associated with the reaction of CLDH with water during its rehydration process, ${ }^{29}$ and the latter is most likely related to interactions between the recrystallised CLDH and the reaction product precipitated from dissolving slag particles. ${ }^{17}$
In a previous study, ${ }^{17}$ where CLDH and HT were incorporated in sodium carbonate-activated slag cements, it was identified that the addition of CLDH accelerates the kinetics of the reaction more than the addition of HT does. This is attributed to the fact that the recrystallisation of CLDH increases the concentration of hydroxide ions and consumes carbonate ions, which leads to a significant rise in the pore solution alkalinity. A similar mechanism is not likely to take place in silicate-based AAS systems, as the increase in hydroxide concentration due to recrystallisation of CLDH in sodium silicate solution would have much less effect on increasing its alkalinity, mainly due to the complexity of the silica speciation in concentrated sodium silicate solutions which buffers the apparent $\mathrm{pH}$ changes. ${ }^{30,31}$ Hence, the changes in reaction kinetics identified in the modified AAS cements assessed may be associated with a combination of fillertype and nucleation templating effects, both speeding up the reaction and favouring precipitation of larger amounts of reaction products. However, to enable the clear identification of the roles played by both CLDH and HT additions in the AAS system, it is important to correlate the reaction kinetics with the reaction products forming in these cements.

\subsection{Early-day reaction product formation}

The selected ATR-FTIR scans in Figure 2 show the structural evolution of the main reaction product forming in these cements, a C-(N)-A-S-H-type gel, ${ }^{15,32}$ during the initial $48 \mathrm{~h}$ after the preparation of the pastes.

For all the samples assessed, the main differences observed in the $\mathrm{C}-(\mathrm{N})-\mathrm{A}-\mathrm{S}-\mathrm{H}$-type gel structure over the time of reaction were 


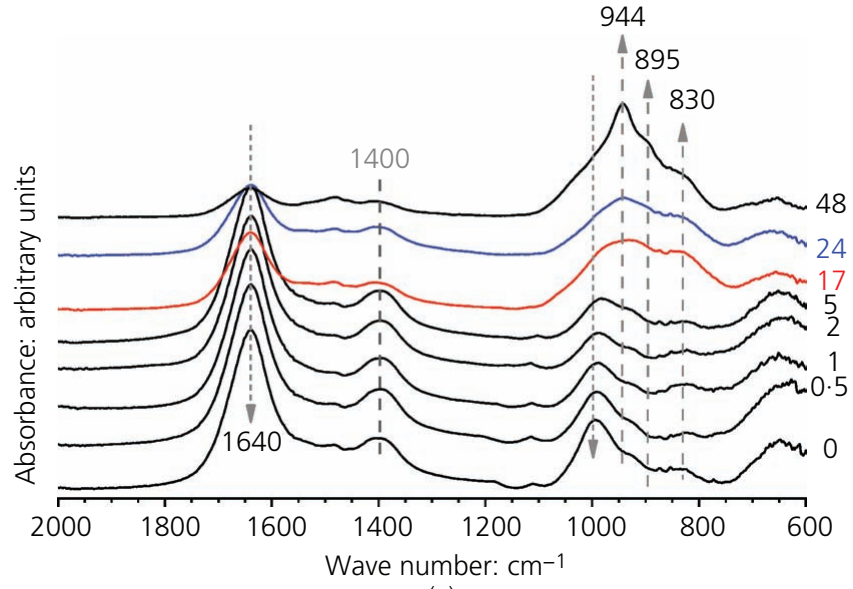

(a)

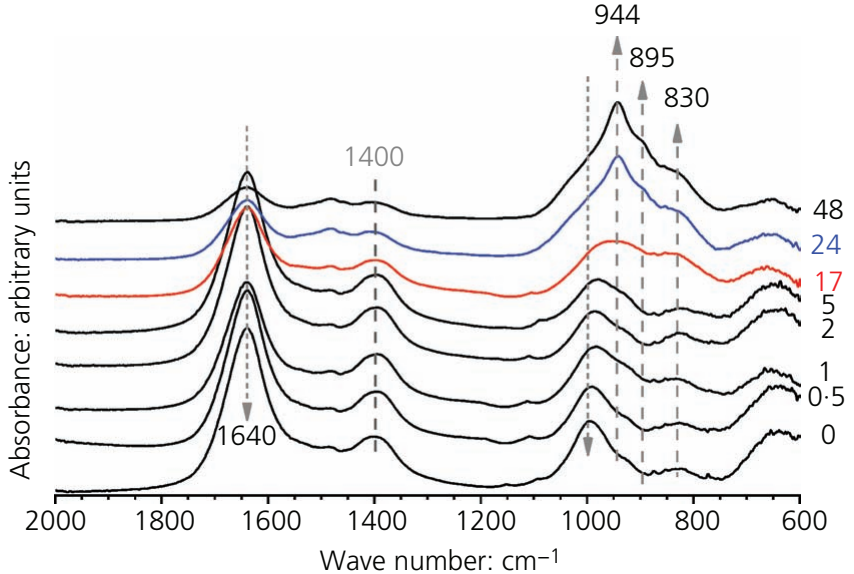

(b)

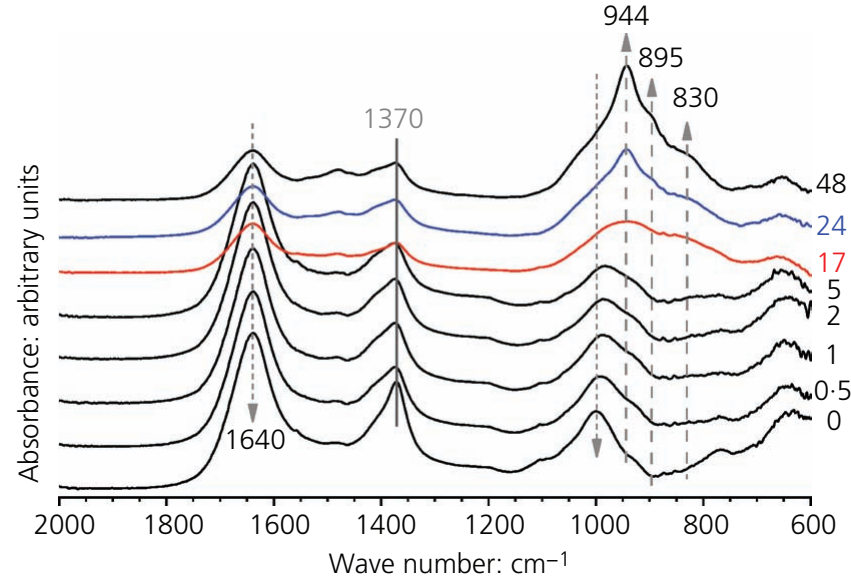

(c)

Figure 2. ATR-FTIR spectra collected as a function of reaction time for (a) AAS paste (reference), (b) AAS paste with $5 \%$ CLDH and (c) AAS paste with $5 \%$ HT

(a) a decrease in the intensity of the band centred at $1640 \mathrm{~cm}^{-1}$ assigned to the bending vibration of the $\mathrm{H}-\mathrm{O}$ bond in water associated with the AAS paste ${ }^{33}(b)$ a decrease in the intensity of the band centred at $1000 \mathrm{~cm}^{-1}$ characteristic of $(\mathrm{Si}, \mathrm{Al})-\mathrm{O}$ bonds of tetrahedral silicates in melilite-type phases, ${ }^{34}$ representing the anhydrous slag; and (c) an increase in intensity, and broadening, of the bands between 1000 and $800 \mathrm{~cm}^{-1}$ assigned to the stretching, bending and asymmetric vibration of $\mathrm{Si}-\mathrm{O}-(\mathrm{Si}, \mathrm{Al})$ bonds as well as $\mathrm{Al}-\mathrm{O}$ within $\mathrm{AlO}_{4}$ groups ${ }^{35-37}$ present in $\mathrm{C}-(\mathrm{N})-$ A-S-H-type gels.

The decrease in the intensity of the broad band centred at $1640 \mathrm{~cm}^{-1}$, which contains contributions from vibration modes of both chemically bonded $\left(\sim 1640 \mathrm{~cm}^{-1}\right)$ and free water $\left(\sim 1660 \mathrm{~cm}^{-1}\right)^{38}$ present in the reaction products of these cements, is consistent with the consumption of water during formation of the $\mathrm{C}-(\mathrm{N})-\mathrm{A}-\mathrm{S}-\mathrm{H}-\mathrm{typ}$ gel, as the reaction progresses.

Correlating these observations with the timescales of the calorimetry results (Figure 1), it is clear that during the first hours of reaction, negligible changes in the structure of the anhydrous slag are taking place, consistent with the pre-induction period identified in the heat release curves. After $17 \mathrm{~h}$ of reaction, both AAS with 5\% CLDH and AAS with 5\% HT reached their maximum heat flow rate, while in the AAS paste without these additives, the acceleration period had just started at this time. Despite the differences in the kinetics of the reaction, very similar ATR-FTIR spectra were observed for the three samples measured at this time (Figure 2), each featuring the initial formation of a broad band between 900 and $1000 \mathrm{~cm}^{-1}$ corresponding to $\mathrm{C}-(\mathrm{N})$ A-S-H-type gels.

After $24 \mathrm{~h}$ of reaction, all of the samples presented deceleration of heat release and started to set. At this time of the reaction, a sharp and high-intensity band with a maximum at $944 \mathrm{~cm}^{-1}$, along with a shoulder at about $895 \mathrm{~cm}^{-1}$, was observed in the ATR-FTIR spectra of AAS with either 5\% CLDH or 5\% HT (Figures 2(b) and $2(\mathrm{c}))$. These bands are mainly attributed to the $\mathrm{Si}-\mathrm{O}-(\mathrm{Si}, \mathrm{Al})$ bonds in the chain-type silicate structure in the C-(N)-A-S-H-type gel, ${ }^{39}$ and its identification is consistent with what has been 
Layered double hydroxides modify the reaction of sodium silicate-activated slag cements

Ke, Bernal and Provis reported in other studies for alkali-activated slag cements. ${ }^{36,40}$ The fact that the distinctive band at $944 \mathrm{~cm}^{-1}$ is identified at earlier times of the reaction in AAS with either $5 \%$ CLDH or 5\% HT compared to the reference sample demonstrates that the addition of CLDH or HT expedites the kinetics of the reaction of AAS, which is consistent with the trends observed by isothermal calorimetry (Figure 1).

The addition of either CLDH or HT does not seem to alter the main binding phase structure, as similar spectra were observed at $48 \mathrm{~h}$ for all three samples assessed, without notable shifting of the vibrational modes. One significant difference between AAS with CLDH (Figure 2(b)) and with HT (Figure 2(c)) was observed between 1300 and $1500 \mathrm{~cm}^{-1}$, attributed to the antisymmetric stretching vibration of the $\mathrm{C}=\mathrm{O}$ bond in carbonates. ${ }^{41}$ The distinctive band at $1370 \mathrm{~cm}^{-1}$ observed in Figure 2(c) corresponds to the interlayer carbonate groups in the HT that was added into this mix. ${ }^{41,42}$ This indicates that the incorporated HT has not significantly dissolved or reacted with the activator solution at this time of reaction. However, the same is not necessarily true of the CLDH, and so it is important to understand the interaction of this additive directly with the activator solution in order to determine its influence on the overall reaction process.

Figure 3 shows the XRD patterns of CLDH that has been allowed to recrystallise by immersion in the same sodium silicate solution used for activating slag, compared with the diffraction patterns of the commercial HT and the thermally prepared CLDH. After $7 \mathrm{~d}$

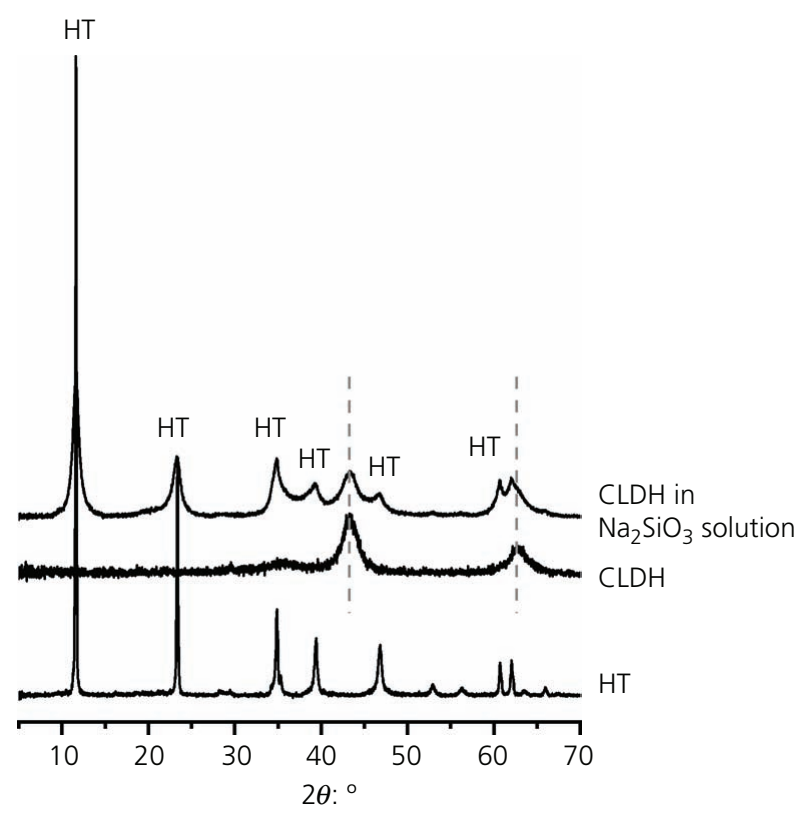

Figure 3. XRD patterns of commercial $\mathrm{HT}$, thermally treated HT (CLDH) and the recrystallised HT-like phase formed after reacting the CLDH for $7 \mathrm{~d}$ with the sodium silicate activator solution. The grey dashed lines indicate the main reflections of periclase (magnesium oxide, Powder Diffraction File (PDF) 01-071-1176) of reaction, most of the CLDH recrystallised into an HT-like phase with lower crystallinity than the commercial HT. The small fraction of CLDH that remains unchanged consists mostly of magnesium oxide. Thus, the magnesium/aluminium ratio in the recrystallised HT-like phase formed could be lower than that of the commercial HT.

The recrystallisation reaction of this CLDH in water or electrolyte solutions is normally fast and approaches completion, ${ }^{7,17}$ and the incomplete reaction of $\mathrm{CLDH}$ in sodium silicate activator solutions might be related to its high viscosity, which hindered the surface hydrolysis process. ${ }^{29,43,44}$ For the HT-like phase recrystallised from CLDH in sodium silicate solution, the interlayer species should be mainly hydroxyl groups and water molecules. Intercalation of polymeric silicon $(\mathrm{Si})$ groups in the interlayers could be possible; however, it is not evident in this study, as the polymerised silica groups would significantly increase the basal spacing of the recrystallised product. ${ }^{45}$ The concentration of the sodium silicate solution used as the activator solution may be sufficiently high that the polymerised silica groups formed in the aqueous phase ${ }^{46}$ become too large to be accommodated into the interlayers of the HT-like phase.

\subsection{Evolution of phase assemblage at later age}

The phase assemblage after $90 \mathrm{~d}$ of curing of AAS with the addition of either CLDH or HT is very similar to that of the reference paste. As shown in Figure 4, the main reaction product formed was a C-(N)-A-S-H-type gel, together with a significant amount of the HT-like phase and traces of vaterite (due to weathering during sample pre-conditioning prior to analytical testing). Neither magnesium oxide nor brucite $\left(\mathrm{Mg}(\mathrm{OH})_{2}\right)$ was identified in samples after $90 \mathrm{~d}$ of curing (Figure 4). This indicates that the magnesium oxide remaining after initial CLDH rehydration (Figure 3) could potentially be incorporated into the HT-like phase forming in these cements.

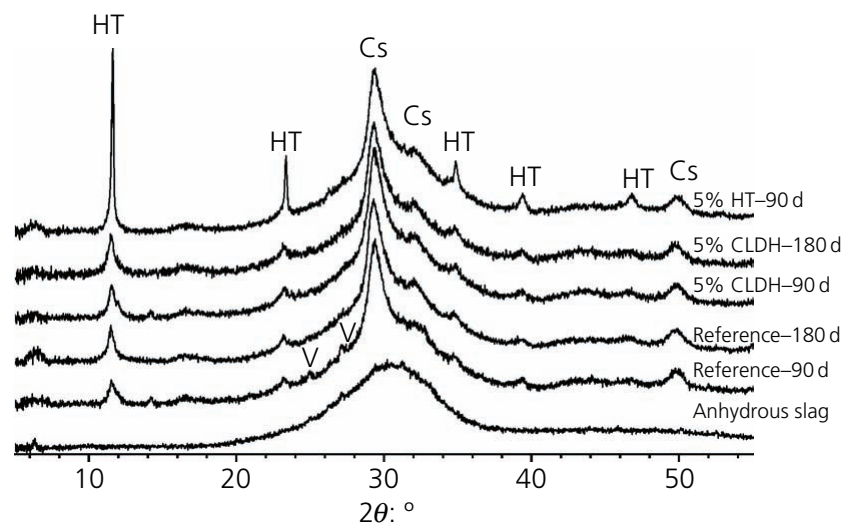

Figure 4. XRD patterns of anhydrous slag and AAS paste samples after $90 \mathrm{~d}$ of curing, where Cs is C-(N)-A-S-H gel (an aluminiumsubstituted tobermorite-like phase, PDF 00-019-0052), HT is hydrotalcite (PDF 00-014-0525) and $V$ is vaterite 
Layered double hydroxides modify the reaction of sodium silicate-activated slag cements

Ke, Bernal and Provis
The main difference between HT-modified and CLDH-modified samples according to XRD (Figure 4) was the crystallinity of the HT-like phase formed. In the AAS samples with zero or $5 \%$ CLDH addition, wide basal reflection peaks centred at around $11 \cdot 6^{\circ}(2 \theta)$ were identified, consistent with the formation of lowcrystallinity HT-like phases previously identified in sodium silicate-activated slag cements ${ }^{8,20}$ and in sodium carbonateactivated slag cements with CLDH addition. ${ }^{17}$ However, in the AAS sample with HT addition, a sharp and narrow reflection peak was identified, indicating the presence of a highly crystalline HTlike phase in this binder. This is attributed to the addition of HT into this cement, which did not extensively dissolve or react with the activator solution, as observed in Figure 2(c).
The BSE images of the AAS pastes after $90 \mathrm{~d}$ of ageing are shown in Figure 5. The light grey angular particles are partially reacted slag grains; the grey regions between the remnant slag particles correspond to the main binding phase, consisting mainly of C-(A)-S-H-type gel and additional reaction products such as the HT-like phase. ${ }^{47}$ The regions darker in greyscale intensity than the general binder are associated with phases containing lighter elements (including pore space), and in alkali-activated slag cement, such regions mostly correspond to regions rich in HT-like phases. ${ }^{8,20}$ For AAS cements without LDH modification, the HTlike rich regions are commonly seen as the inner reaction product rims surrounding the partially reacted or fully reacted slag particles, ${ }^{48,49}$ as observed in Figure 5(a). However, for samples

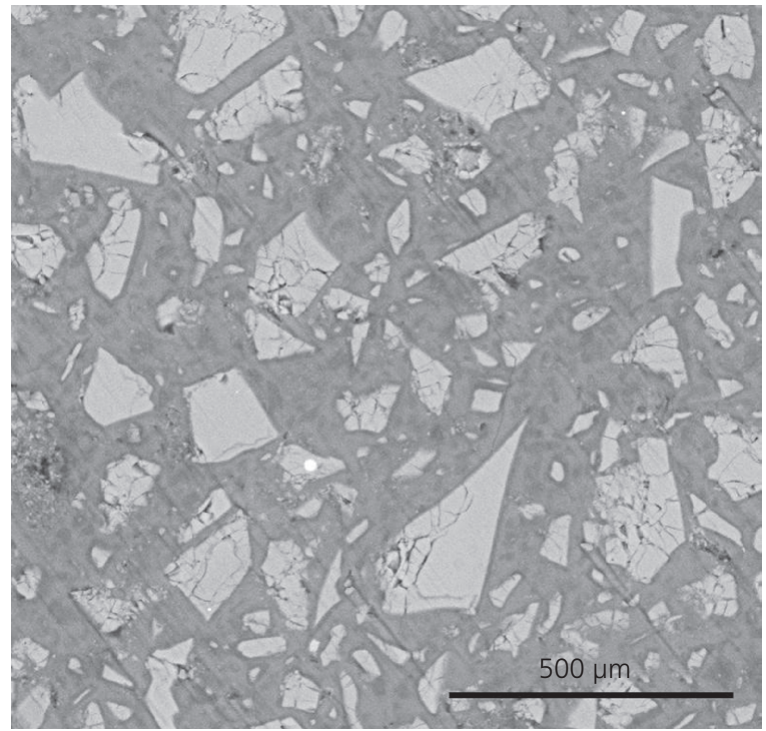

(a)

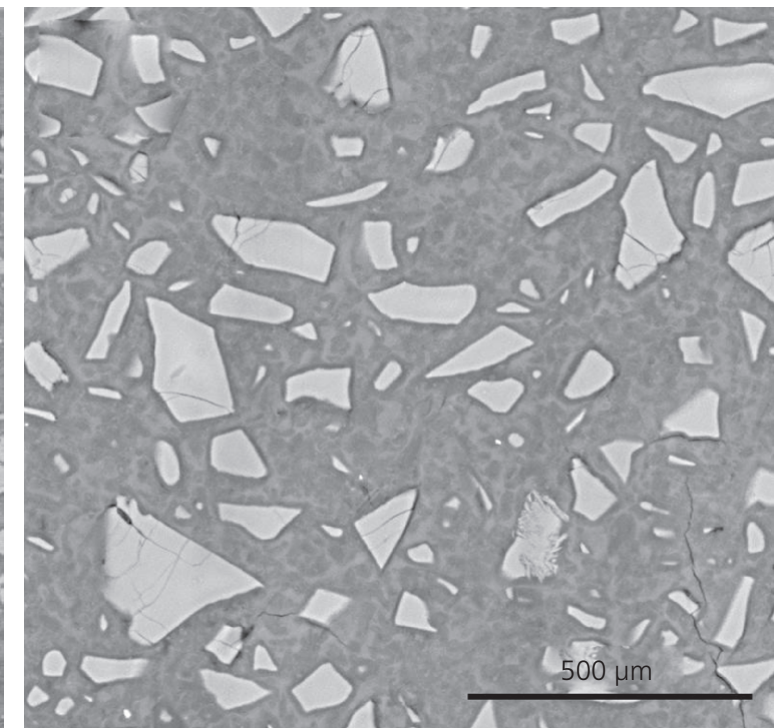

(b)

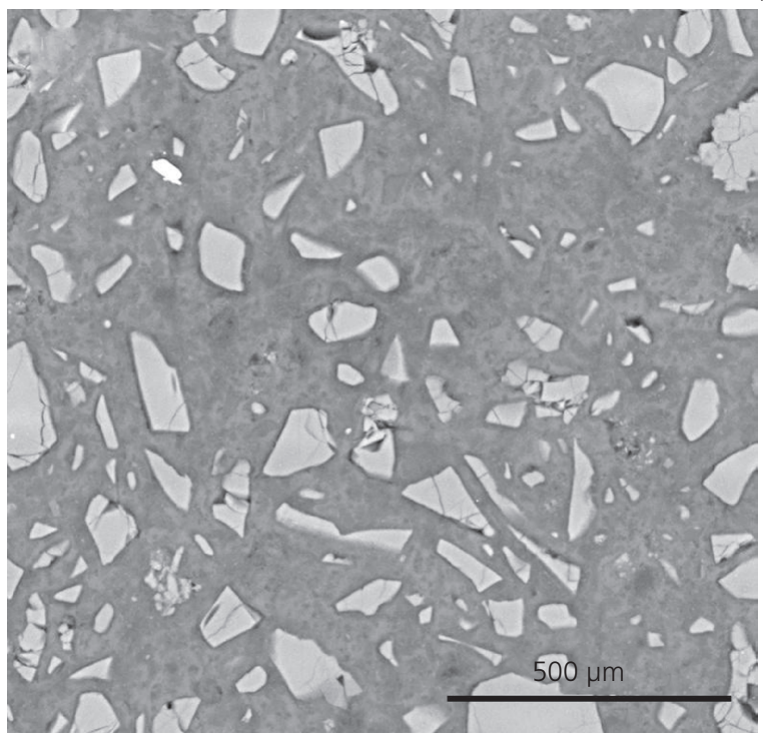

(c)

Figure 5. BSE images of AAS pastes cured for $90 \mathrm{~d}$ : (a) reference; (b) with $5 \% \mathrm{CLDH}$; (c) with $5 \% \mathrm{HT}$ 
incorporating either CLDH or HT, the dark grey regions observed between the slag grains (Figures 5(b) and 5(c)) correspond to the recrystallised HT-like phase from the added $\mathrm{CLDH}^{4,5}$ or the added HT and appeared to be closely intermixed with the main binding phase. However, between Figures 5(b) and 5(c), the microstructures appear very similar, consistent with the XRD results (Figure 4) showing comparable phase assemblages for both of the LDH-containing samples.

Figure 6 shows the atomic ratio correlations calculated from the EDX spots taken from the AAS pastes studied. The plot of calcium/(silicon + aluminium) against aluminium/silicon (Figure 6(a)) can be used to understand the bulk calcium/ (silicon + aluminium) ratio of C-(N)-A-S-H-type gels present in the analysed region, while the magnesium/silicon against aluminium/silicon plot (Figure 6(b)) is used to evaluate the overall magnesium/aluminium ratios in the HT-like phases forming in AAS ${ }^{8,20}$ In Figure 6(a), the spreads of the data points from different AAS samples were almost overlapping within the same range of values, suggesting that the calcium/(silicon + aluminium) ratio of the C-(A)-S-H-type gel forming in these cements is about the same, even with $5 \mathrm{wt} . \%$ of either CLDH or HT added to the mixtures. The calcium/(silicon + aluminium) ratios (Figure 6(a)) range between $0 \cdot 6$ and $1 \cdot 2$, and these values are generally consistent with the reported chemical compositions of C-(N)-A-SH-type gels forming in AAS and in synthetic gels, whose bulk calcium/(aluminium + silicon) ratios range from $0 \cdot 7$ to $1 \cdot 3 .^{50-52}$ There are also a few scattered data points with very low calcium/ (aluminium + silicon) ratios; these also have high aluminium/ silicon ratios and so are identified as regions in which LDH phases are prominent and intermixed with the C-(N)-A-S-H-type gel. In comparison with the data reported in the literature for AAS cement with similar magnesium oxide content, the calcium/ (aluminium + silicon) ratio observed here is slightly higher. ${ }^{8,27,50}$ This might relate to the relatively high availability of calcium oxide from the slag precursor used here, which has a calcium/ silicon molar ratio of $1 \cdot 2$.

In Figure 6(b), there is a linear trend in the data for all samples, yielding a magnesium/aluminium ratio of around 2. This matches the magnesium/aluminium ratio of the LDH phase that is normally observed in long-term-cured alkali-activated slag samples, which is around $2 \cdot 1 .^{20,53}$ This suggests that the addition of either CLDH or HT does not seem to have any significant impact on changing the layer cation compositions of the HT-like phases forming in silicate-activated AAS, consistent with the observations by XRD (Figure 4) for these cements.

\section{Conclusions}

Both HT and CLDH additives have a similar effect in accelerating the kinetics of the reaction of AAS cement, shortening the induction periods and accelerating the formation of C-(N)-A-S-Htype gels. However, the incorporation of HT did not seem to affect the total heat release compared with the reference mix, which suggests that the changes in the kinetics of the reaction induced by this additive are mainly associated with a filler effect. Conversely, the incorporation of CLDH led to higher total heat release, associated with incongruent dissolution of this compound and its recrystallisation in hydrous (but carbonate-free) form. Silicate substitution within the interlayer of $\mathrm{Mg}$-Al $\mathrm{LDH}$ phases

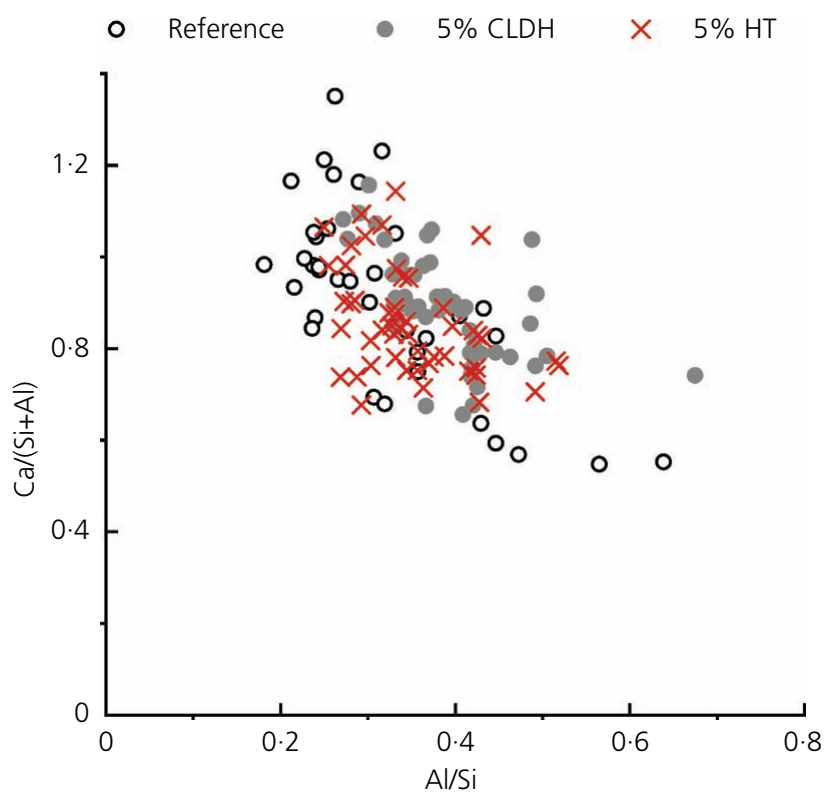

(a)

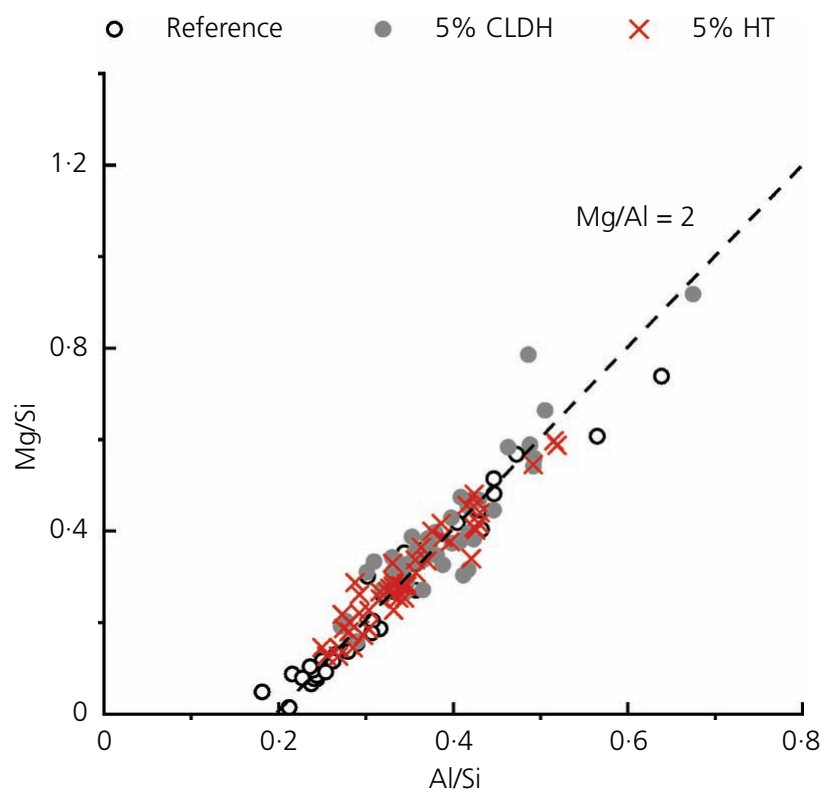

(b)

Figure 6. Atomic elemental ratios calculated from EDX data for $90 \mathrm{~d}$ cured AAS paste (reference) and pastes with $5 \% \mathrm{CLDH}$ and $5 \% \mathrm{HT}$, respectively: (a) $\mathrm{Ca} /(\mathrm{Si}+\mathrm{Al})$ plotted against $\mathrm{Al} / \mathrm{Si}$, (b) Mg/Si plotted against $\mathrm{Al} / \mathrm{Si}$ 
Layered double hydroxides modify the reaction of sodium silicate-activated slag cements Ke, Bernal and Provis was not observed here, even when the CLDH recrystallised within a sodium silicate solution environment.

The crystallinity of HT-like phases in AAS is modified by the incorporation of LDH. However, apart from this, the modified AAS pastes showed very similar microstructural features and phase compositions compared with those of non-modified cements. Control of the kinetics of the reaction and an increase in the HT content within AAS pastes are achievable by adding either HT or CLDH.

\section{Acknowledgements}

This research was funded by the European Research Council (ERC) under the EU's Seventh Framework Programme (FP7/2007-2013)/ERC Grant Agreement Number 335928 (GeopolyConc). The participation of S.A.B. in this research was partially funded by the UK Engineering and Physical Sciences Research Council through Grant EP/M003272/1.

\section{REFERENCES}

1. Duan X and Evans DG (2006) Layered Double Hydroxides. Springer, Berlin, Germany.

2. Miyata S (1975) The syntheses of hydrotalcite-like compounds and their structures and physico-chemical properties I: the systems $\mathrm{Mg}^{2+}$ $-\mathrm{Al}^{3+}-\mathrm{NO}_{3}{ }^{-}, \mathrm{Mg}^{2+}-\mathrm{Al}^{3+}-\mathrm{Cl}^{-}, \mathrm{Mg}^{2+}-\mathrm{Al}^{3+}-\mathrm{ClO}_{4}{ }^{-}, \mathrm{Ni}^{2+}-\mathrm{Al}^{3+}-\mathrm{Cl}^{-}$and $\mathrm{Zn}^{2+}-\mathrm{Al}^{3+}-\mathrm{Cl}^{-}$. Clays and Clay Minerals 23(5): 369-375.

3. Sato T, Fujita H, Endo T, Shimada M and Tsunashima A (1989) Synthesis of hydrotalcite-like compounds and their physico-chemical properties. Reactivity of Solids 5(2-3): 219-228.

4. Theiss FL, Couperthwaite SJ, Ayoko GA and Frost RL (2014) A review of the removal of anions and oxyanions of the halogen elements from aqueous solution by layered double hydroxides. Journal of Colloid and Interface Science 417: 356-68.

5. Morimoto K, Anraku S, Hoshino J, Yoneda T and Sato T (2012) Surface complexation reactions of inorganic anions on hydrotalcite-like compounds. Journal of Colloid and Interface Science 384(1): 99-104.

6. Miyata S (1983) Anion-exchange properties of hydrotalcite-like compounds. Clays and Clay Minerals 31(4): 305-311.

7. Ke X, Bernal SA and Provis JL (2017) Uptake of chloride and carbonate by $\mathrm{Mg}-\mathrm{Al}$ and $\mathrm{Ca}-\mathrm{Al}$ layered double hydroxides in simulated pore solutions of alkali-activated slag cement. Cement and Concrete Research 100: 1-13.

8. Bernal SA, San Nicolas R, Myers RJ et al. (2014) MgO content of slag controls phase evolution and structural changes induced by accelerated carbonation in alkali-activated binders. Cement and Concrete Research 57: 33-43.

9. Yoon S, Moon J, Bae S et al. (2014) Chloride adsorption by calcined layered double hydroxides in hardened Portland cement paste. Materials Chemistry and Physics 145(3): 376-386.

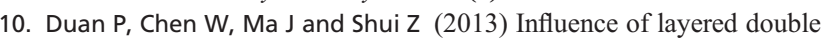
hydroxides on microstructure and carbonation resistance of sulphoaluminate cement concrete. Construction and Building Materials 48: 601-609.

11. Yang Z, Fischer $\mathrm{H}$ and Polder R (2015) Laboratory investigation of the influence of two types of modified hydrotalcites on chloride ingress into cement mortar. Cement and Concrete Composites 58: 105-113.

12. Provis JL, Palomo A and Shi C (2015) Advances in understanding alkaliactivated materials. Cement and Concrete Research 78(A): 110-125.

13. Provis JL and Bernal SA (2014) Geopolymers and related alkaliactivated materials. Annual Review of Materials Research 44: 299-327.
14. Provis JL (2014) Geopolymers and other alkali activated materials: why, how, and what? Materials and Structures 47(1): 11-25.

15. Richardson IG, Brough AR, Groves GW and Dobson CM (1994) The characterization of hardened alkali-activated blast-furnace slag pastes and the nature of the calcium silicate hydrate (C-S-H) paste. Cement and Concrete Research 24(5): 813-829.

16. Wang SD and Scrivener KL (1995) Hydration products of alkaliactivated slag cement. Cement and Concrete Research 25(3): 561-571.

17. Ke X, Bernal SA and Provis JL (2016) Controlling the reaction kinetics of sodium carbonate-activated slag cements using calcined layered double hydroxides. Cement and Concrete Research 81: 24-37.

18. Ke X, Bernal SA, Hussein OH and Provis JL (2017) Chloride binding and mobility in sodium carbonate-activated slag pastes and mortars. Materials and Structures 50(6): 252.

19. Ke X, Criado M, Provis JL and Bernal SA (2018) Slag-based cements that resist damage induced by carbon dioxide. ACS Sustainable Chemistry \& Engineering 6(4): 5067-5075.

20. Ben Haha M, Lothenbach B, Le Saout G and Winnefeld F (2011) Influence of slag chemistry on the hydration of alkali-activated blastfurnace slag - part I: effect of MgO. Cement and Concrete Research 41(9): 955-963.

21. Myers RJ, Lothenbach B, Bernal SA and Provis JL (2015) Thermodynamic modelling of alkali-activated slag cements. Applied Geochemistry 61: 233-247.

22. Kanezaki E (1998) Thermal behavior of the hydrotalcite-like layered structure of $\mathrm{Mg}$ and Al-layered double hydroxides with interlayer carbonate by means of in situ powder HTXRD and DTA/TG. Solid State Ionics 106(3-4): 279-284.

23. Mourad MCD, Mokhtar M, Tucker MG et al. (2011) Activation and local structural stability during the thermal decomposition of $\mathrm{Mg} / \mathrm{Al}-$ hydrotalcite by total neutron scattering. Journal of Materials Chemistry 21(39): 15479-15485.

24. Bernal SA, San Nicolas R, van Deventer JSJ and Provis JL (2015) Water content modifies the structural development of sodium metasilicateactivated slag binders. ALCONPAT Journal 5(1): 29-40.

25. Shi C and Day RL (1995) A calorimetric study of early hydration of alkali-slag cements. Cement and Concrete Research 25(6): 1333-1346.

26. Fernández-Jiménez A and Puertas F (1997) Alkali-activated slag cements: kinetic studies. Cement and Concrete Research 27(3): 359-368.

27. Ben Haha M, Lothenbach B, Le Saout G and Winnefeld F (2012) Influence of slag chemistry on the hydration of alkali-activated blastfurnace slag - part II: effect of $\mathrm{Al}_{2} \mathrm{O}_{3}$. Cement and Concrete Research 42(1): 74-83.

28. Huanhai Z, Xuequan W, Zhongzi X and Mingshu T (1993) Kinetic study on hydration of alkali-activated slag. Cement and Concrete Research 23(6): 1253-1258.

29. Tamura H, Mita K, Tanaka A and Ito M (2001) Mechanism of hydroxylation of metal oxide surfaces. Journal of Colloid and Interface Science 243(1): 202-2027.

30. Svensson IL, Sjoberg S and Ohman LO (1986) Polysilicate equilibria in concentrated sodium silicate solutions. Journal of the Chemical Society, Faraday Transactions 1: Physical Chemistry in Condensed Phases 82(12): 3635-3646.

31. Nordström J, Nilsson E, Jarvol P et al. (2011) Concentration- and pHdependence of highly alkaline sodium silicate solutions. Journal of Colloid and Interface Science 356(1): 37-45.

32. Myers RJ, Bernal SA, Provis JL, Gehman JD and van Deventer JSJ (2015) The role of Al in cross-linking of alkali-activated slag cements. Journal of the American Ceramic Society 98(3): 996-1004.

33. Ismail I, Bernal SA, Provis JL, Hamdan S and Deventer JSJ (2013) Drying-induced changes in the structure of alkali-activated pastes. Journal of Materials Science 48(9): 3566-3577. 
Layered double hydroxides modify the reaction of sodium silicate-activated slag cements

Ke, Bernal and Provis
34. Sharma SK, Yoder HS and Matson DW (1988) Raman study of some melilites in crystalline and glassy states. Geochimica et Cosmochimica Acta 52(8): 1961-1967.

35. Handke M and Mozgawa W (1993) Vibrational spectroscopy of the amorphous silicates. Vibrational Spectroscopy 5(1): 75-84.

36. Bernal SA, Provis JL, Rose V and Mejía de Gutierrez R (2011) Evolution of binder structure in sodium silicate-activated slag-metakaolin blends. Cement and Concrete Composites 33(1): 46-54.

37. García-Lodeiro I, Fernández-Jiménez A, Blanco MT and Palomo A (2008) FTIR study of the sol-gel synthesis of cementitious gels: C-S-H and N-A-S-H. Journal of Sol-Gel Science and Technology 45(1): 63-72.

38. Yu P, Kirkpatrick RJ, Poe B, McMillan PF and Cong X (1999) Structure of calcium silicate hydrate (C-S-H): near-, mid-, and far-infrared spectroscopy. Journal of the American Ceramic Society 82(3): 742-748.

39. García-Lodeiro I, Fernández-Jiménez A, Blanco MT and Palomo A (2007) FTIR study of the sol-gel synthesis of cementitious gels: $\mathrm{C}-\mathrm{S}-\mathrm{H}$ and N-A-S-H. Journal of Sol-Gel Science and Technology 45(1): 63-72.

40. Bernal SA, Rodríguez ED, Mejía de Gutiérrez R, Provis JL and Delvasto S (2012) Activation of metakaolin/slag blends using alkaline solutions based on chemically modified silica fume and rice husk ash. Waste and Biomass Valorization 3(1): 99-108.

41. Huang CK and Kerr PF (1960) Infrared study of the carbonate minerals. The American Mineralogist 45(3-4): 311-324.

42. Hernandez-Moreno M, Ulibarri M, Rendon JL and Serna C (1985) IR characteristics of hydrotalcite-like compounds. Physics and Chemistry of Minerals 12(1): 34-38.

43. Yang $X$, Zhu W and Yang Q (2008) The viscosity properties of sodium silicate solutions. Journal of Solution Chemistry 37(1): 73-83.

44. Tamura H, Tanaka A, Mita K and Furuichi R (1999) Surface hydroxyl site densities on metal oxides as a measure for the ion-exchange capacity. Journal of Colloid and Interface Science 209(1): 225-231.
45. Depège C, El Metoui FZ, Forano C et al. (1996) Polymerization of silicates in layered double hydroxides. Chemistry of Materials 8(4) 952-960.

46. Knight CTG, Balec RJ and Kinrade SD (2007) The structure of silicate anions in aqueous alkaline solutions. Angewandte Chemie International Edition 46(43): 8148-8152.

47. Bernal SA, Provis JL, Rose V and Mejía de Gutiérrez R (2013) Highresolution X-ray diffraction and fluorescence microscopy characterization of alkali-activated slag-metakaolin binders. Journal of the American Ceramic Society 96(6): 1951-1957.

48. Brough AR and Atkinson A (2002) Sodium silicate-based, alkaliactivated slag mortars: part I. strength, hydration and microstructure. Cement and Concrete Research 32(6): 865-879.

49. Ben Haha M, Le Saout G, Winnefeld F and Lothenbach B (2011) Influence of activator type on hydration kinetics, hydrate assemblage and microstructural development of alkali activated blast-furnace slags. Cement and Concrete Research 41(3): 301-310.

50. Myers RJ, Bernal SA, San Nicolas R and Provis JL (2013) Generalized structural description of calcium-sodium aluminosilicate hydrate gels the cross-linked substituted tobermorite model. Langmuir 29(17): 5294-5306.

51. Puertas F, Palacios M, Manzano H et al. (2011) A model for the C-A$\mathrm{S}-\mathrm{H}$ gel formed in alkali-activated slag cements. Journal of the European Ceramic Society 31(12): 2043-2056.

52. L'Hôpital E, Lothenbach B, Le Saout G, Kulik D and Scrivener K (2015) Incorporation of aluminium in calcium-silicate-hydrates. Cement and Concrete Research 75: 91-103.

53. Richardson I (2013) Clarification of possible ordered distributions of trivalent cations in layered double hydroxides and an explanation for the observed variation in the lower solid-solution limit. Acta Crystallographica Section B: Structural Science, Crystal Engineering and Materials 69(6): 629-633.

\section{How can you contribute?}

To discuss this paper, please submit up to 500 words to the journal office at journals@ice.org.uk. Your contribution will be forwarded to the author(s) for a reply and, if considered appropriate by the editor-in-chief, it will be published as a discussion in a future issue of the journal.

ICE Science journals rely entirely on contributions from the field of materials science and engineering. Information about how to submit your paper online is available at www.icevirtuallibrary.com/page/authors, where you will also find detailed author guidelines. 